\title{
Aristotle vs.
}

\section{Boole: A case}

\section{of the Universe}

\section{of Discourse}

\section{KAREL ŠEBELA}

Faculty of Arts

Palacky University Olomouc

Křižlkovského 12

77180 Olomouc

karel.sebela@upol.cz

\section{ABSTRACT}

I will present a case study comparing Aristotelian and modern predicate logic. The traditional square of opposition embodied certain relations between propositions. When rewritten into the language of modern logic, the relations embodied in the traditional square mostly disappear. As a matter of fact, some conservative versions of predicate logic, namely sortal logic, preserve relations in the square. I will argue that the explanation of the fact is that modern logic accepts the socalled principle of wholistic reference. The principle was stated initially by Boole with respect to his concept of a so-called universe of discourse. According to the principle, each and every proposition refers to the universe of discourse as such. The difference between Aristotelian and modern logic will thus be portrayed as a difference in the concept of what are we talking about in the universal propositions.*

"This is a result of the research funded by the Czech Science Foundation as the project GA ČR 19-06839S Non-classical Interpretation of the Aristotelian Logic and Theory of Predication." 


\section{INTRODUCTION}

Although Aristotelian logic ${ }^{1}$ is interpreted as only a minor part of canonical modern extensional logic, namely first-order logic, there still remains one point deliberately neglected and unmentioned, this being the assumption of nonempty terms. When Lukasiewicz proved the completeness and decidability of Aristotelian $\operatorname{logic}{ }^{2}$, it was in respect to the universe of unary first-order predicates, but predicates which are nonempty, i.e. which denote at least one individual. Without this assumption,

1 By the term "Aristotelian logic", I mean rather broadly the logic of Aristotelian tradition. It is true that some followers of Aristotle changed some of his essential ideas, so I would like to keep the most "orthodox" line possible.

2 See Lukasiewicz 1957.
Aristotelian logic as part of modern extensional first-order logic lost its essential features: the square of opposition collapses and several hitherto valid modes of syllogism yield invalid patterns of inference. The reason, as it is usually claimed, is that first-order logic does not require the nonemptiness of terms and in this sense is much broader than Aristotelian logic. In this article, I would like to demonstrate that the key lies not in the question of the nonemptiness of terms, but in the concept of the universe of discourse as the subject of our propositions.

\section{ARISTOTELIAN VS. MODERN}

\section{LOGIC}

The above-mentioned problem can be illustrated with the item of the square of 
opposition $^{3}$. In the square, there is e.g. a relation of subalternation: the relation holds between universal (SaP, A for brevity) and corresponding particular judgement (SiP, I for brevity) (for simplicity, we will consider the affirmative judgements only). The relation of subalternation implies that if A judgement is true, we may immediately infer that I is also true. The inference SaP/SiP is consequently a pattern of valid inference.

If these judgements are rewritten into the language of modern first-order logic, in short FOL, we will get $\forall \mathrm{x} S(\mathrm{x})$ $\rightarrow \mathrm{P}(\mathrm{x})$ for $\mathrm{A}$ and $\exists \mathrm{x} \mathrm{S}(\mathrm{x}) \wedge \mathrm{P}(\mathrm{x})$ for $\mathrm{I}$. The point is that under some conditions the first formula, $\forall \mathrm{x} \mathrm{S}(\mathrm{x}) \rightarrow \mathrm{P}(\mathrm{x})$, can be true but under the same conditions the second formula, $\exists \mathrm{x} \mathrm{S}(\mathrm{x}) \wedge \mathrm{P}(\mathrm{x})$, is false, so it could not be the case that we can infer the second formula from the first one. The above-mentioned condition is simply that the predicate " $\mathrm{S}$ " is empty, i.e. nothing falls under the predicate. Under this condition, the antecedent of the formula $\forall \mathrm{x} \mathrm{S}(\mathrm{x}) \rightarrow \mathrm{P}(\mathrm{x})$ is false (no $\mathrm{x}$ is $\mathrm{S}$ ). The entire formula is now an implication and according to the definition of implication in FOL, an implication with a false antecedent is true (ex falso quodlibet). Formula $\exists \mathrm{x} S(\mathrm{x}) \wedge \mathrm{P}(\mathrm{x})$ is also a conjunction and at least one of the conjuncts, namely $\mathrm{S}(\mathrm{x})$, is false. According to the definition of conjunction in FOL, a conjunction with at least one false conjunct is false. In summary, if the predicate $S$ is empty, the inference

3 A general overview of the topic may be found in Parsons, 2017. The Czech reader may consult on this issue Vlasáková, 2015. from A to I is invalid, so generally in FOL the inference from A to I is invalid.

\section{SORTAL LOGIC}

Timothy Smiley has demonstrated that a relatively con servative modification of FOL will ensure the validity of the essential features of Aristotelian logic, namely, the square of the opposition mentioned above $^{4}$. This modification is called sortal first-order logic (SOL). SOL is a version of first-order logic. The key concept of SOL is obviously the concept of a sortal. The simplest and widely accepted interpretation of sortals is that they provide a criterion for counting items of a kind, as it is in Cocchiarella's definition of a sortal concept - "a socio-genetically developed cognitive ability or capacity to distinguish, count and collect or classify things" 5 . Typical examples of sorts are tigers, cats, tables, etc., in short, countable items.

SOL now introduces a so-called sortal quantification. The key idea could be stated as follows: in a sentence e.g. all men are mortal, its canonical interpretation in first-order logic tells us that for every object it is the case that if the object is $\mathrm{S}$, then the object is also P. This sounds somewhat odd because the original sentence does not seem to be "about" all objects. In SOL, the original sentence is reformulated in a way that the universal quantifier does not quantify over all individuals, but over the individuals which fall under $S$, put briefly, quantifies over all Ss. If we wish

See Smiley, 1962.

Cocchiarella, 1977, p. 441. 
to reformulate $\mathrm{SaP} / \mathrm{SiP}$ inference in SOL, we will get this:

$\underline{\text { All As are B - } \quad \forall a \mathrm{~B}(a)}$

Some As are B - $\exists a \mathrm{~B}(a)$

This inference is valid in SOL. So, as it was said above, a relatively conservative modification of FOL will preserve the validity of subalternation (and consequently of the square of opposition in general). This fact brings us to the question as to what is really the key difference between Aristotelian logic and FOL?

\section{UNIVERSE OF DISCOURSE}

The original idea was that the difference is in the assumption of nonempty terms in Aristotelian logic, because first-order logic does not require the nonemptiness of terms. This reason could be called into doubt with some success, however, for in first-order logic the grammatical subject of its formulae is always an individual constant or individual variable. First-order logic therefore requires each individual constant to denote an object in the domain of quantificationwhich is usually understood as a set of "existing" objects. Individual variables in first-order logic range over a domain of individuals. In first-order logic there exists the requirement that the domain of quantification should be nonempty. In a nutshell, any possible grammatical subject of a first-order logical formula either denotes an object in the domain (constant) or ranges over a nonempty domain of individuals and therefore in a certain sense the latter logic also requires the nonemptiness of its terms.
In conclusion, the difference between first-order logic and Aristotelian logic does not necessarily turn on the issue of the emptiness of its terms.

We will follow the idea that the key lies in the concept of the universe of discourse. ${ }^{6}$ George Boole was the first who used the expression "universe of discourse" in English. It was concretely in his book The Laws of Thought (1854). For Boole, "universe of discourse is in the strictest sense the ultimate subject

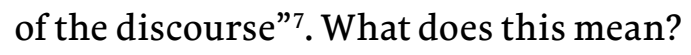
"In every discourse, whether of the mind conversing with its own thoughts or of the individual in his intercourse with others, there is an assumed or expressed limit within which the subjects of its operation are confined. The most unfettered discourse is that in which the words we use are understood in the widest possible application, and for them the limits of discourse are co-extensive with those of the universe itself". Universe of discourse is thus the most extensive class of all objects, symbolised by 1 . In Boole's logic, any subsequent specialization of the subject of the proposition is construed as a concept based on the concept of the universe of discourse in addition to whatever else it involves, e.g. to say "Water is fluid" is equivalent to "Water is a fluid thing", or "human" has a logical form "entity, that is a human". John Corcoran calls it the principle of wholistic reference - "each and every ...

The following passage about Boole is already contained in my article Šebela (2018).

Boole 2006, p. 30.

Boole 2006, p. 30. 
proposition refers to the universe of dis-

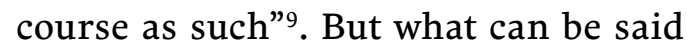
about the nature of the objects, which constitutes the universe of discourse? Boole at the beginning of his 1854 book wrote that there is a dispute concerning the meaning of the signs used as names in the process of thinking. According to Boole, "By some it is maintained, that they represent the conceptions of the mind alone; by others, that they represent things"10. In other words, Boole discusses the clash between idealism and realism and he himself claims that signs represent things. This statement is, in my view, a good illustration of John Corcoran's thesis that the concept of logic as a formal ontology begins with Boole (in contrast to Aristotle's project of logic as formal epistemology $)^{11}$. To refute the position that names represent the conceptions of mind, means to refute the epistemological disputes about the possibility of the human mind to acknowledge objective reality. This observation can be reinforced by the fact that Boole's original concept presupposes only one fixed universe of discourse, but in the 1854 version the pluralistic multi-universe framework is proposed. This enlargement (or deliberation) makes logic in a way independent from epistemological limitations of knowledge, because in this framework the given universe of discourse is a matter of choice.

10 Boole 2006, p. 18.

11 Corcoran 2003, p. 278n.

\section{UNIVERSE OF DISCOURSE IN} MODERN LOGIC

FOL now takes the idea of the universe of discourse from Boole. In FOL, the universe of discourse is simply the set of all things one's quantifiers range over. In SOL, in contrast, the universe of discourse is divided into groups, into sorts. Even the variables in SOL are variables which range over the appropriate sort only. If we wish, however, to introduce "classical" quantifiers, we could easily implement them into the theory (the technical details are not important here). The main difference between FOL and SOL thus lies precisely in the "nature" of the universe of discourse. How does this difference influence the validity or invalidity of the above-mentioned subalternation?

The answer is in the problem of the subject of proposition, simply in the task of what we are talking about in a given proposition. Modern logic in general shares Boole's idea, already cited, that the "universe of discourse is in the strictest sense the ultimate subject of the discourse". For FOL, the subject of each and every proposition is the universe of discourse as such, in its "most unfettered" sense. As mentioned above, John Corcoran calls it the principle of wholistic reference. Once again, according to the principle, "each and every ... proposition refers to the universe of discourse as such". This idea, as it stands, sounds quite odd, but has become a widely accepted part of logic textbooks under the name of the Boolean interpretation of categorical statements ${ }^{12}$. In the influential book

12 Copi 2014, p. 193. 
An Introduction to Logic and Scientific Method, by Cohen and Nagel, one can read, for example, that "the proposition All street-cleaners are poor declares that in its universe of discourse there are no individuals who are both street-cleaners and not poor"13. Boolean interpretation has a significant consequence - if the proper subject is the universe of discourse, which is always nonempty, then there is no need for the grammatical subject of the sentence to denote anything. Concretely, if we take the proposition that All street-cleaners are poor, it seems unproblematic to rewrite it in the language of FOL as $\forall \mathrm{xP}(\mathrm{x})$. This formula says that all objects are poor. For this reason we need to input an antecedent into the given formula, namely the antecedent, that if any object is a street-cleaner, then it is poor. Thus, the appropriate formula of FOL is $\forall \mathrm{x} \mathrm{S}(\mathrm{x}) \rightarrow$ $\mathrm{P}(\mathrm{x})$. Categorical propositions can thus become hypotheses about the universe, hypotheses with possibly empty grammatical subjects. This is why the truth of the categorical propositions in FOL does not require the nonemptiness of its grammatical subjects. This liberation only holds, however, for the universal propositions, because particular propositions are taken as existential statements about the universe, e.g. the proposition Some street-cleaners are poor is taken as affirming the existence of at least one object, which is both a streetcleaner and poor. If universal propositions in FOL do not require, however, the nonemptiness of its grammatical

13

Cohen and Nagel 1998, p. 40. subjects but particular propositions do require it, the subalternation is blocked. The price of this move is the fact that subalternation very often seems an unproblematically valid inference, as e.g. Cohen and Nagel observe: "The conclusion we have reached, that universals do not imply the existence of any verifying instances, while particulars do imply it, will doubtless seem paradoxical to the reader"14.

\section{UNIVERSE OF DISCOURSE IN ARISTOTELIAN LOGIC}

Can there be some analogue of this concept in Aristotelian logic? The very term is out of the discussion here, of course, but terms such as "entity" or "being" are a traditional part of Aristotelian vocabulary and can be invoked here. So, does the sum of all the entities in Aristotelian logic plays the same (or at least a similar) role as the universe of discourse in modern logic? The answer is no. This answer is also a key to the difference between the logic in the question of the validity of the square of opposition. For Aristotle, in fact, the differences between various kinds of objects are of a logical importance.

Firstly, as John Corcoran states it, "in his logic, Aristotle did not recognise the universal term 'entity' or 'thing"'15. The absence of evidence, however, is not evidence of absence, so it would be appropriate to search for some more direct support. There is in fact an indication that Aristotle did not allow for

Cohen and Nagel 1998, p. 42.

Corcoran 2003, p. 272. 
his content words to have a universal extension. It is his well-known aporia generis argument. The original passage in Metaphysics concerns the concept of being and one and is as follows:

"But it is not possible that either one or being should be a single genus of things; for the differentiae of any genus must each of them both be and be one, but it is not possible for the genus taken apart from its species (any more than for the species of the genus) to be predicated of its proper differentiae; so that if one or being is a genus, no differentia will either be or be one"16

Aristotle's argument can be (for the concept of being) reconstructed as follows:

No genus is predicated of its differentiae. Being is predicated of its differentiae (or else they would not be).

Being is therefore not a genus.

I do not want to evaluate this argument here, but I would just like to conclude that this argument means that the most natural counterpart of Boole's concept of the universe of discourse cannot play an analogical role in Aristotelian logic. If being is not a genus and genus is predicated univocally, then being is not even a univocal concept.

Generally, for Aristotelian logic it is an important thing that the universe of objects is divided and grouped into parts. Some indirect evidence can be offered for this claim. The special case is the concept of so-called term negation. ${ }^{17}$$$
17
$$

Met. B, 998b24-27.

The following passage is taken from Šebela, Sedlár (2018).
Term negation can be traced back to Aristotle's De Interpretatione ${ }^{18}$ where so-called indefinite names and verbs are studied. These names and verbs are obtained (in English) by adding a prefix such as 'not-', 'un-' or 'non-' to regular names and verbs. 'Not-man' and 'notill' are, for example, indefinite names. Aristotle observed that sentence pairs containing a name (verb) in one sentence and the corresponding indefinite name (verb) in the other are contrary, i.e. they cannot be simultaneously true:

"If it is true to say 'It is not-white', it is also true to say 'it is not white': for it is impossible that a thing should simultaneously be white and be not-white."19

Such pairs are not necessarily contradictory, i.e. one may be false without the other being true:

"everything is equal or not equal, but not everything is equal or unequal, or if it is, it is only within the sphere of that which is receptive of equality. " 20

Hence, statements of the form ' $S$ is not- $\mathrm{P}$ ' are not equivalent to ' $\mathrm{S}$ is not $\mathrm{P}$ ':

"In establishing or refuting, it makes some difference whether we suppose the expressions 'not to be this' and 'to be not-this' are identical or different in meaning, e.g., 'not to be white' and 'to be not white'. For they do not mean the same thing, nor is 'to be not-white' the negation of 'to be white', but 'not to be white' [is]. "21

It is apparent from Met. 1055 that Aristotle thinks of term negation as being

18 De Intepr.16a30n, 16b 11n.

19 Pr.An. 51b42-52a4.

20 Met.105510n.

21 Pr.An.51b5-10. 
connected to the genus of a predicate there may be things that are neither $P$ nor not-P, but no such thing can be found within the genus of $P$.

The concept of a category mistake is additional indirect evidence. ${ }^{22}$ In Aristotle, one can find a discussion of two kinds of what is currently called a category mistake, i.e. the mistake when entities belonging to a particular category are presented as if belonging to another category. In the Topics, he refers to sentences such as "angle and knife are sharp" 23 . The one who claims that the "sharp" applies the same way to the angle and knife would commit a category mistake because the angle and the knife are entities of different categories (here it is quantity and substance). This kind of a category mistake is, however, a kind of equivocation and can be removed by pointing out the variety of ways in which we understand the sharpness of the angle and the knife. In addition, the equivocation can be explained without reference to a category mistake, and some equivocations cannot be explained by reference to a category mistake, for example, if we attribute the sharpness to the smell and color, which are both qualities. Another kind of categorical error, a proper category mistake, is in the Second Analytics ${ }^{24}$. Aristotle speaks of an essential and accidental predication, and says, with an obvious reference to Plato's doctrine of ideas, that the "predicates which do not signify

\footnotetext{
22 The following passage is taken (and translated) from my book Šebela (2015).

23 Top. 107a3-17.

24 An. Post. 83a30-33.
}

substance must be predicates of some other subject, and nothing can be white which is not also other than white". The error that Aristotle has in mind here can be illustrated by the phrase "White is white". Whiteness is an accident, and if we want to talk about some idea of whiteness, "white in itself", which might be in place of the subject of the judgement, then it should be possible to predicate about such a subject, for example, to be white. "Being white" is, however, an accidental predicate, i.e. an appropriate thing may possibly not have it. This would lead to the absurdity that the white color might possibly not be white. This kind of category mistake differs from the previous one because it cannot be removed by reference to the different meanings of the word.

In summary, for Aristotle it is the conviction that the universe is so to speak sorted into a different group of a great logical importance.

\section{UNIVERSE OF DISCOURSE IN SORTAL LOGIC}

What is the situation in SOL? The proposition All street-cleaners are poor is also about the universe of discourse, but in this case the universe is sorted, so we are speaking only about the appropriate sort in the given proposition. If the sort are simply street-cleaners, then we can rewrite in SOL as $\forall s \mathrm{P}(s)$. The formula is thus not an implication, so it is not a hypothesis about the universe. For the variables in SOL there is now the same requirement as in FOL, namely the requirement that the domain of quantification should be nonempty. This means, 
in the case of SOL, that sorts are always is caused by the fact that the subject of nonempty. This is the key difference, these propositions is the universe of diswhich makes subalternation in SOL course in FOL. To harmonise modern and valid. Aristotelian logic in this point we only need to sort the universe of discourse

\section{CONCLUSION}

As we have seen, subalternation is a valid inference in Aristotelian logic, but is invalid in FOL. The reason for the invalidity is in the different logical form of universal propositions. The difference and make the appropriate sort be the subject of these propositions. Needless to say, to sort the universe of discourse into parts is an idea which seems to be very close to the Aristotelian conception of categorisation of the world. 


\section{ABBREVIATIONS}

Aristotle

An. Post.

De interpr.
Analytica posteriora

De interpretatione
Met. Metaphysica

Pr. An. Analytica priora

Top. Topica

\section{REFERENCES}

Boole, G. (2006). An Investigation of the Laws of Thought. Urbana, Illinois: Project Gutenberg.

Cocchiarella, N. (1977). Sortals, natural kinds and re-dentification. Logique et Analyse 20, p. 438-474.

Cohen, M.R., Nagel, E. (1998). An Introduction to Logic and Scientific Method. New Delhi: Allied Publishers Ltd.

Copi, I., Copi, C., McMahon, K. (2014). Introduction to Logic. Fourteenth edition. Harlow: Pearson Prentice Hall.

Corcoran, J. (2004). The Principle of Wholistic Reference. Manuscrito 30, p. 493-505.

Corcoran, J. (2003). Aristotle's Prior Analytics and Boole's Laws of Thought. History and Philosophy of Logic 24, p. 261-288.

Łukasiewicz, Jan L. (1957). Aristotle's Syllogistic: From the Standpoint of Modern Formal Logic. $2^{\text {nd }}$ edition. Oxford: Clarendon Press.
Parsons, T. (2017). The Traditional Square of Opposition. The Stanford Encyclopedia of Philosophy (Summer 2017 Edition), Zalta, N. (ed.), URL = https://plato.stanford.edu/archives/sum2017/entries/square/.

Smiley, T. (1962). Syllogism and Quantification. The Journal of Symbolic Logic,27, p. 58-72.

Šebela, K. (2018). Internal Negation and Universe of Discourse: Kant and Boole. Czech and Slovak Journal of Humanities, to appear.

Šebela, K. (2015). Variace na témata aristotelské logiky. Plzeň: Západočeská univerzita v Plzni.

Šebela, K., Sedlár, I. (2018). Term Negation in First-Order Logic. Logique et Analyse, to appear.

Vlasáková, M. (2015). Logický čtverec a otázka existence (in Czech). Filosofický časopis 63, p. 77-93. 